\title{
Fundamental elements of constant volt/hertz induction motor drives based on dSPACE DS1104 controller
}

\author{
Siti Nursyuhada Mahsahirun ${ }^{1}$, Nik Rumzi Nik Idris ${ }^{2}$, Zulkifli Md. Yusof ${ }^{3}$, Tole Sutikno ${ }^{4}$ \\ ${ }^{1,3}$ Faculty of Manufacturing \& Mechatronic Engineering Technology, Universiti Malaysia Pahang, Malaysia \\ ${ }^{2}$ Power Electronics \& Drives Research Group, School of Electrical Engineering, Universiti Teknologi Malaysia, Malaysia \\ ${ }^{4}$ Department of Electrical Engeenering, Universitas Ahmad Dahlan, Yogyakarta, Indonesia \\ ${ }^{4}$ Embedded System and Power Electronics Research Group (ESPERG), Yogyakarta, Indonesia
}

\section{Article Info \\ Article history: \\ Received Jan 17, 2020 \\ Revised Jul 18, 2020 \\ Accepted Aug 27, 2020 \\ Keywords: \\ Constant volt/hertz Induction motor drives Space vector modulation $\mathrm{V} / \mathrm{Hz}$ drive \\ Voltage source inverter}

\begin{abstract}
An induction motor (IM) has been the workhorse of the industry for decades. It is due to its robustness, simple construction, requiring less maintenance and cheap. One of the most widely adopted IM drive control schemes for industrial applications is the open-loop constant $\mathrm{V} / \mathrm{Hz}$. In this paper, the important elements of an open-loop constant $\mathrm{V} / \mathrm{Hz}$ drives are presented. These include the fundamental concept of a constant $\mathrm{V} / \mathrm{Hz}$ scheme, the voltage source inverter (VSI) and its modulation schemes. Techniques that are commonly used to solve problems of low-speed operation and rotor speed regulation are briefly described. Simulations using MATLAB/Simulink package are used to help in illustrating these fundamental concepts. Finally, simple laboratory-scale experiments are conducted to implement the constant $\mathrm{V} / \mathrm{Hz}$ control scheme on a $1 / 4 \mathrm{hp}$ induction motor. The constant $\mathrm{V} / \mathrm{Hz}$ control is implemented using the DS1104 controller board with the C codes automatically generated from the Simulink model. A closer look at the current waveform when $\mathrm{f}_{\mathrm{ref}}=25 \mathrm{~Hz}$ and $12 \mathrm{~Hz}$ and its respective Fourier analysis are presented. The results show that the high-frequency harmonic contents around the switching frequency can be observed for both cases, and the voltage waveform presents more spike noises in constrast to current waveform.
\end{abstract}

This is an open access article under the CC BY-SA license.

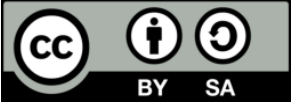

\section{Corresponding Author:}

Siti Nursyuhada Mahsahirun,

Faculty of Manufacturing \& Mechatronic Engineering Technology

Universiti Malaysia Pahang

26600 Pekan, Pahang, Malaysia

Email: ct_nursyuhada@ymail.com

\section{INTRODUCTION}

Inverter based induction motor (IM) drives system has been widely used in the industry replacing the conventional direct-on-line (DOL), the star-delta (Y- $\Delta$ ) and others starter methods [1-4] as well as their gear integration (gearbox transmission system) [5-7] for variable speed drive (VSD). Figure 1 shows a simple illustration of the conventional versus power electronics inverter IM drives. This technology has rapidly grown since the era of power electronics was born in the mid $20^{\text {th }}$ century until nowadays $[8,9]$. Many engineers in the manufacturing sectors are forced to familiarize and have to decide whether or not to merge the technology into their readily established conventional systems. The main advantage of this technology is energy efficiency which translated to the life long operational cost [10]. Apart from that, this technology comes with implementation cost and engineers need to make sure it is highly reliable, robust, and manageable under their circumstances. 


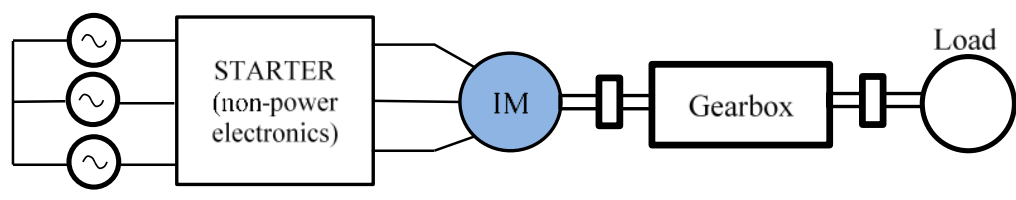

(a)

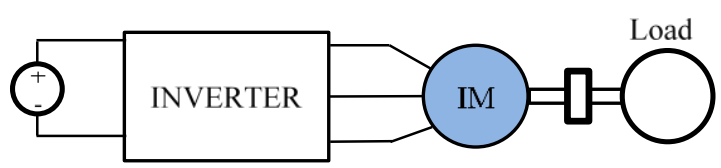

(b)

Figure 1. Basic block diagram of 3-phase IM driveline (a) with starter and gearbox (b) with inverter

Similar to other electronic devices, power electronics inverter can cause significant downside to the overall system particularly when operated in a harsh and unpredictable environment in a factory due to heat, humidity, vibration, EMI, and others [11]. Often times, manufacturing engineers do not necessarily have sufficient knowledge of IM drives that would finally tradeoff downtime cost [12]. Getting the knowledge through proper courses can be time-consuming while self-synthesizing the knowledge through numerous journals reading with different standards and terminology could be overwhelming [13].

In this paper, the fundamental elements of the inverter-based IM drives method, namely the constant $\mathrm{V} / \mathrm{Hz}$, is presented. The problems associated with the low-speed operation speed regulation are discussed and possible solutions are suggested. This paper is organized in the following manner. In Section 2, important concepts of constant $\mathrm{V} / \mathrm{Hz}$ control and major components that are typically used in IM industrial drives are presented and explained. This section will also present the problems associated with a constant $\mathrm{V} / \mathrm{Hz}$ control scheme at low-speed operation. Section 3 presents the simulation and experimental methodology while Section 4 discusses the simulation and experimental results. Finally, Section 5 presents the conclusion.

\section{INDUCTION MOTOR DRIVES}

IM is one of the highly robust, high torque-to-inertia ratio and high efficient type of motor [14, 15]. On top of that, IM is also known for its simple construction, easy to maintain and relatively cheaper in price. It has been applied in numerous applications in household appliances and in various industrial sectors. In general, there are two types of control methods for IM drives: scalar control and vector control. For highperformance applications, vector control techniques such as field-oriented control (FOC) [16] and direct torque control (DTC) [17] are normally employed. Those applications that requiring high-performance torque control such as industrial CNC machines, elevators, and recently in electric vehicles [18]. For low to medium performance applications, such as fan, blower, pump and compressor, scalar control techniques are normally preferred [19].

The most popular scalar control techniques, known as constant $\mathrm{V} / \mathrm{Hz}$ (or constant $\mathrm{V} / \mathrm{F}$ ), is the simplest means to achieve linear control of IM's torque and speed [20, 21]. This control mechanism ensures the operation of the IM at its rated flux, thus prevents the rotor core magnetization reaching its saturation and run in its hysteresis loop. This is accomplished by maintaining the ratio between the air-gap voltage and the frequency constant at all speeds. The open-loop version of this control scheme is the most widely used control technique in industrial drives due to its simplicity, cost effectiveness and reliability. The implementation of a constant $\mathrm{V} / \mathrm{Hz}$ scheme does not require a high-performance processor, and with the open-loop operation, a high precision speed sensor is not needed. The performance of the open-loop constant $\mathrm{V} / \mathrm{Hz}$ drives, however, deteriorates at low-speed region because the terminal voltage no longer approximates the back-EMF due to the significant voltage drop across the stator impedance, hence maintaining constant $\mathrm{V} / \mathrm{Hz}$ will not exactly result a constant air-gap flux.

A typical open-loop constant V/Hz IM drive system is shown in Figure 2. In this configuration, the input power is obtained from the 3-phase power supply, which is rectified by the 3-phase diode rectifier to produce a DC voltage. To obtain a stiff DC voltage, a large electrolytic capacitor is normally connected to the output of the rectifier. It consists of a 3-phase voltage source inverter (VSI) with input DC voltage acquired from a 3-phase diode rectifier circuit. The switching signals for the 3-phase VSI is generated by the pulse width modulator based on the frequency and voltage magnitude inputs. The constant $\mathrm{V} / \mathrm{Hz}$ block produces the magnitude of the voltage reference $\left(V_{\text {ref }}\right)$, based on the frequency reference $\left(f_{\text {ref }}\right)$. If a diode rectifier is used as the front-end converter, braking power cannot be fed back to the utility, instead, it will be dumped to 
the DC link capacitor, C. Therefore, a crowbar circuit is typically added to the DC link circuit to avoid the capacitor voltage from exceeding its maximum allowable value during dynamic braking. This is done by discharging the access charge via the resistor. The following sections discuss the fundamental concept and main elements of the control scheme.

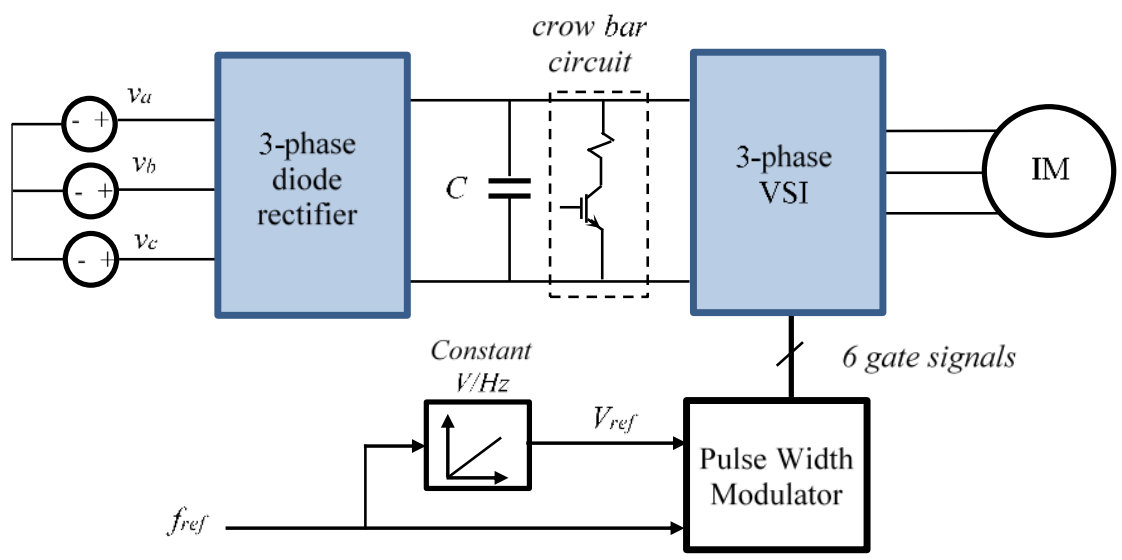

Figure 2. Open-loop constant $\mathrm{V} / \mathrm{Hz}$ drive

\subsection{Constant V/Hz controller}

The torque of the IM can be written in terms of the rotor current and air-gap flux as

$$
T_{e}=K I_{r}^{\prime} \phi_{a g} \sin \delta
$$

where $K$ is a constant, and $\delta$ is the angle between $I_{r}^{\prime}$ and $I_{m}$. Figure 3(a) shows the per-phase equivalent circuit of an IM and its corresponding phasor diagram. For small slip operation, $\delta$ is close to $90^{\circ}$ (i.e. $\theta \approx 0$ ) and hence (1) can be written as

$$
T_{e}=K I_{r}^{\prime} \phi_{a g}
$$

When the rotor is running at small slip, $R_{r}^{\prime} \gg 2 \pi f_{s l} L_{l r}^{\prime}$, hence combining (1) and (2), we can write

$$
T_{e}=K^{\prime} \phi_{a g}^{2} f_{s l}
$$

Therefore, to maximize the torque capability, the air-gap flux has to be maximized, and the maximum possible value without saturation would be the rated value. The magnetizing current of an IM is responsible for producing the air-gap flux. From the per-phase equivalent circuit of the IM shown in Figure 3, the magnetizing current $\mathrm{I}_{\mathrm{m}}$ is the current that flows through the magnetizing inductance Lm. Thus, from the perphase steady-state equivalent circuit point of view, in order to maintain the rated air-gap flux at any frequency, it is necessary to ensure that $I_{m}$ is at its rated value at all frequencies. As can be seen from the equivalent circuit, the magnetizing current $\mathrm{I}_{\mathrm{m}}$ can be written as shown in (4).

$$
I_{m}=\frac{E_{g}}{2 \pi f L_{m}} \rightarrow I_{m, \text { rated }}=\frac{E_{g, \text { rated }}}{2 \pi f_{\text {rated }} L_{m}}
$$

According to (4), the magnitude of the magnetizing current can be maintained constant at its rated by maintaining the ratio of the back emf, $E_{g}$, to the frequency, $f\left(\mathrm{E}_{\mathrm{g}} / \mathrm{f}\right)$, equals to the ratio at the rated values, i.e. $\mathrm{E}_{\mathrm{g}, \text { rated }} / \mathrm{f}_{\text {rated }}$, at all frequencies. If the frequency is reduced, $E_{g}$ has to be reduced proportionally to maintain constant $I_{m \text {,rated }}$. At high speed, $E_{\mathrm{g}}$ is large and the voltage drop across the stator leakage inductance $L_{l s}$ and stator resistance $R_{s}$ is relatively small; under this condition, $E_{g} / f$ is maintained constant by maintaining $V_{s} / f$ constant. In other words, we can assume 


$$
\frac{E_{g}}{f} \simeq \frac{V_{s}}{f}=\frac{V_{s, \text { rated }}}{f_{\text {rated }}}
$$

For a given frequency, $f$, the magnitude of the stator voltage, therefore, can be determined from (5). At low frequency, the approximation in (5) cannot be justified since the magnitudes of $E_{g}$ and $V_{s}$ are small hence the voltage drop across stator impedance becomes significant. To overcome this, a boost voltage is added to compensate for the voltage drop at low frequencies. As the frequency increases, the boost voltage gradually reduced. There are several possible ways of boosting the voltage, the ones that are shown in Figure 4 are based on the non-linear boost as shown in Figure 4(a) and linear boost as shown in Figure 4(b). In either case, the amount of voltage boost is a function of frequency. For instance, using a linear boost, we can derive the expression of the boost voltage by taking the differences between the voltage-frequency relationships with and without the boost. From Figure 3(b),

$$
\begin{aligned}
& \text { Without boost: } V_{1}(f)=\frac{V_{\text {rated }}}{f_{\text {rated }}} f \\
& \text { With boost: } V_{2}(f)=\frac{V_{\text {rated }}-V_{B}}{f_{\text {rated }}} f+V_{B}
\end{aligned}
$$

Therefore, the amount of voltage boost needed is

$$
V_{\text {boost }}(f)=V_{2}(f)-V_{1}(f)=V_{B}-\frac{V_{B}}{f_{\text {rated }}} f
$$

To fed the desired 3-phase $V$ and $f$ to the IM, a 3-phase voltage source inverter (VSI) is used and this is discussed next.

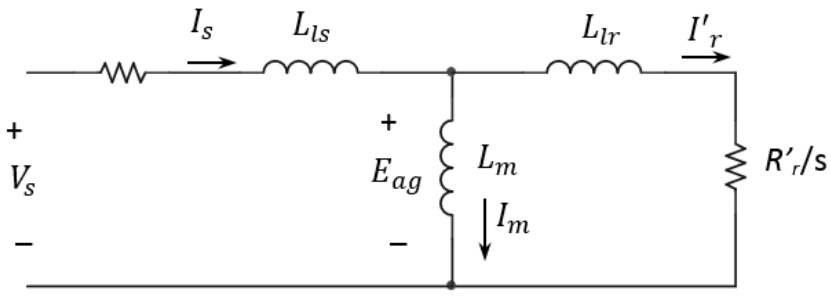

(a)

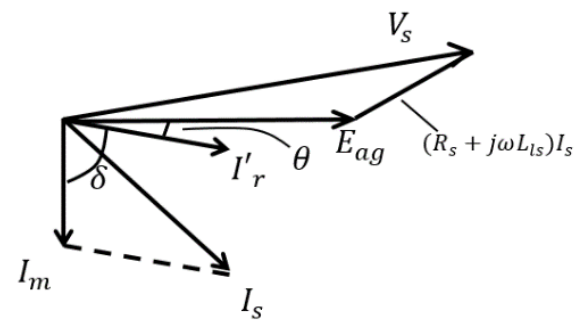

(b)

Figure 3. IM per-phase T-form steady state equivalent circuit model and phasor diagram [22]

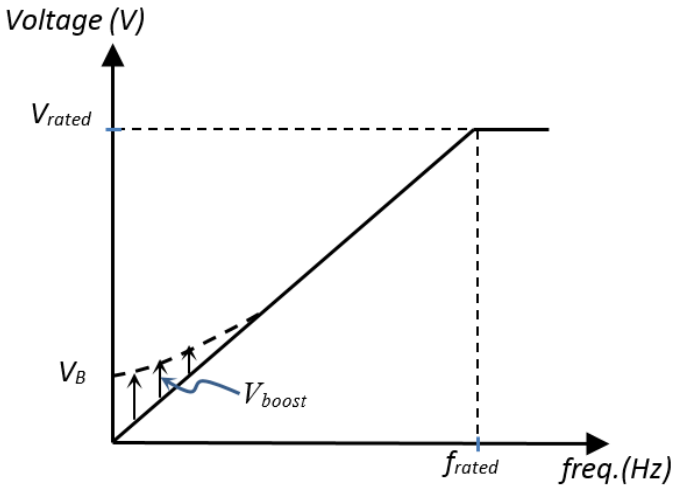

(a)

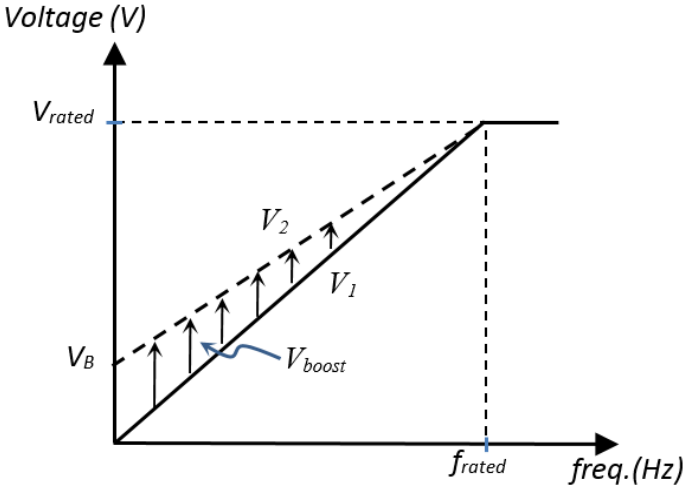

(b)

Figure 4. Boost voltage for constant V/Hz control (a) Non-linear boost; (b) Linear boost 


\subsection{Three-phase inverter}

A three-phase voltage source inverter (VSI) is one of the types of power electronics converter that is used to convert a DC input to an AC output. As shown in Figure 5, a VSI contains 6 power semiconductor devices (with anti-parallel diodes), 2 for each leg. In power converter applications, power semiconductor devices (for example power IGBTs or power MOSFETs) are operated as power switches. They are operated in either cut-off region (turn-off state) or saturation region (turn-on state), this is also known as the switchmode operation. The status of the upper and lower power switches of a leg in a VSI must always be opposite to avoid shoot-through or short circuit. In other words, if an upper switch is turned on, a lower switch has to be turned off. For practical implementation, a so-called blanking time has to be included before the other switch is turned on. This is because a power switch will not immediately be turned off when a turn-off signal is applied at its gate. The duration of the blanking time depends on the type of power switches and can be determined from the data sheets of the switches $[23,24]$. There are various techniques that can be used to control the switches to produce sinusoidal output voltage, however, the most widely adopted technique would be the pulse width modulation (PWM) technique [13]. Using PWM, the output voltage magnitude and frequency can be controlled simultaneously. One of the most popular PWM methods that is commonly targeted in industrial drives is known as the space vector PWM (SV-PWM) $[25,26]$.

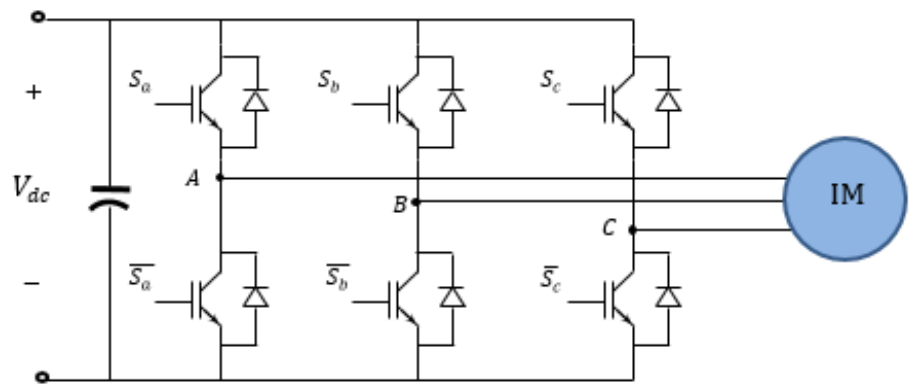

Figure 5. A 3-phase voltage source inverter

\subsection{SV-PWM}

Space vector PWM (SV-PWM) [27] is a modulation technique that is widely adopted for AC-motor drives compared to other techniques, such as sinusoidal PWM (SPWM) [28], because of its excellent compatibility with digital implementation. In other words, using a microprocessor or microcontroller, SVPWM gives less computational burden and easier to implement. Furthermore, with SV-PWM, a better DC voltage utilization can be achieved [29, 30]. In contrast to SPWM, which treats the 3-phase quantities separately, in SV-PWM, the 3-phase quantities are treated using a single equation, known as space vector equations.

In a three 3-phase VSI with three legs, as shown in Figure 4, there are $2^{3}=8$ possible switch configurations, hence eight possible voltage vectors that can be generated or obtained. The possible switch configurations for the three legs and the respective voltage vectors are depicted in Figure 6 . The voltage vectors are labeled as $v_{1}$ to $v_{7} ; 6$ of them are active vectors $\left(v_{1}-v_{6}\right)$ and 2 of them $\left(v_{0}\right.$ and $\left.v_{7}\right)$ are zero voltage vectors. Status ' 1 ' indicates that the upper switch of a leg is 'ON', and the lower switch is 'OFF' and vice versa. For instance, [ $\left.\begin{array}{lll}1 & 0 & 1\end{array}\right]$ means that the upper switches of legs A and C, and the lower switch of leg B are turned on. SV-PWM utilizes these available voltage vectors to synthesize the reference voltage within a sampling period. The space vector of the output for a 3-phase VSI is given by

$$
v=\frac{2}{3} V_{d c}\left(S_{a}+a S_{b}+a^{2} S_{c}\right)
$$

where $V_{d c}$ is the DC link voltage, $S_{a}, S_{b}$, and $S_{c}$ are the switching functions for legs respectively, which equals ' 1 ' if the upper switches are 'ON' and ' 0 ' if the lower switches are 'OFF'.

The reference signals to the SV-PWM can be in the form of the $d-q$ components or of amplitude and angle of the voltage vector. In order to translate the 3-phase voltages to d-q or amplitude angle form, coordinate transformation is used. These transformation is well known as Clarke ( $\alpha \beta)$ [31] and Park (dq) transformations [32]. The reference voltage is synthesized, within a sampling period, by selecting the two adjacent voltage vectors and zero voltage vectors thus maintaining the switching frequency constant. For 
example, if the reference voltage vector, $\boldsymbol{v}_{r e f}$, is located in sector 1 , voltage vectors $\mathrm{v}_{1}, \mathrm{v}_{2}, \mathrm{v}_{0}$ and $\mathrm{v}_{7}$ would be selected and applied within a sampling period. This is illustrated in Figure 7.

It can be shown that, the values of $T_{1}$ and $T_{2}$ within a sampling period $T$ are as:

$$
\begin{aligned}
& T_{1}=\frac{3}{2} \cdot T \cdot v_{r e f}\left(\cos \alpha-\frac{1}{\sqrt{3}} \sin \alpha\right) \\
& T_{2}=\sqrt{3} \cdot T \cdot v_{r e f} \sin \alpha
\end{aligned}
$$

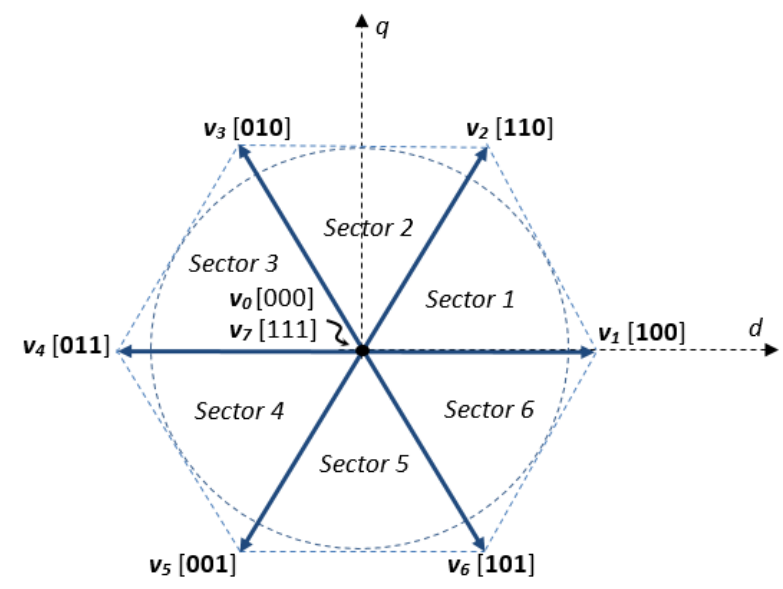

Figure 6. Available voltage space vector for a 3-phase, 2-level, VSI
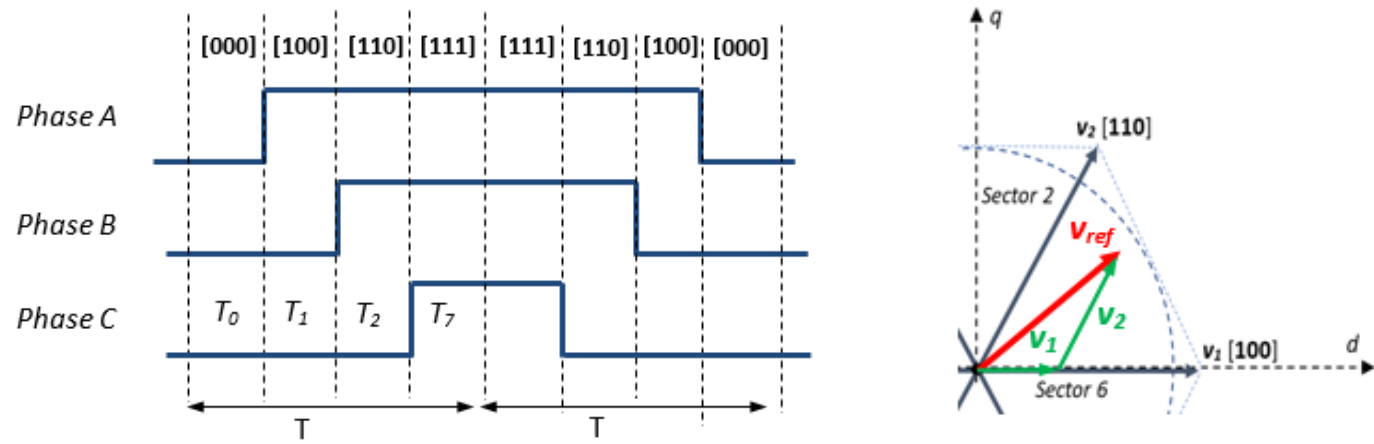

Figure 7. Switching pattern of the 3-phase VSI in Sector 1

In 8 (a) and 8(b), $v_{\text {ref }}$ is the magnitude of the reference vector and $\alpha$ is the angle between the reference voltage and the adjacent vector (to the right of the reference voltage). The interval for zero voltage vector is given by:

$$
T_{o}+T_{7}=T-\left(T_{1}+T_{2}\right)
$$

The ratio between $T_{0}$ and $T_{7}$ essentially controls the amount of triplen harmonic [33] components in the fundamental phase voltage.

\subsection{Improved open-loop constant $\mathrm{V} / \mathrm{Hz}$ scheme}

Unlike synchronous motor which rotates at a synchronous speed even with load variations, in IM, the rotor speed differs from the synchronous speed by the slip speed. To make matters worse, the slip speed varies with load. To overcome this in an open-loop constant $\mathrm{V} / \mathrm{Hz}$ drive, the slip speed is estimated and subsequently added to the reference speed so that the rotor speed will be more or less equal to reference speed. The slip speed can be estimated by estimating the air-gap power, $P_{a g}$, which is obtained by subtracting the input power to the VSI with the losses in the VSI and stator copper and core losses. Once the air-gap power, is obtained, the torque can be estimated as, 
$T_{e}=\frac{P_{a g}}{\omega_{s}}$

Knowing the torque $T_{e}$, and since the airgap flux is kept constant at the rated value, the slip frequency can be estimated from (3). The block diagram of the open-loop constant $\mathrm{V} / \mathrm{Hz}$ with slip compensation scheme is shown in Figure 8. To implement this scheme, we need to measure the DC link voltage, $V_{d c}$, and the input DC current to the VSI, $I_{d c}$. In order to limit the rate of change of the reference frequency, a rate limiter is added. This will ensure that the rotor can catch up with the rotating magnetic field so that the slip frequency can be kept small. The figure also shows the injection of boost voltage, $V_{\text {boost }}$, to the amplitude of the reference voltage, to compensate for the stator impedance drop at low-speed operations. As shown by (6), the amount of boost voltage needed is a function of the frequency.

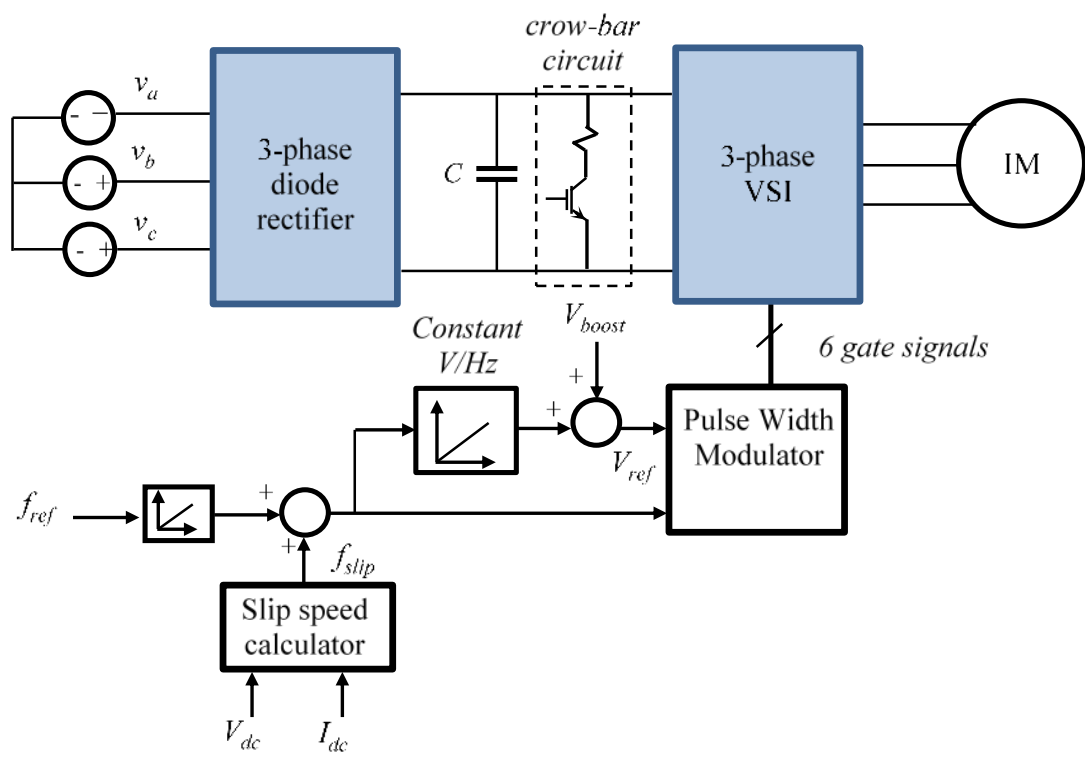

Figure 8. Open-loop constant V/Hz with slip compensation and voltage boost

\section{RESEARCH METHOD}

\subsection{Simulation}

To study the behavior and characteristics of a constant $\mathrm{V} / \mathrm{Hz}$ control IM drive, simulations using MATLAB/Simulink (R2016b) were conducted. The Simulink block diagram of the drive system is as shown in Figure 9(a). The switching frequency is set to $2 \mathrm{kHz}$ and the parameters of a 4-pole, $50 \mathrm{~Hz}, 190 \mathrm{~V}$ with power rating of $186 \mathrm{~W}$ IM are given in Table 1. The same IM is also used in the experiment, which will be discussed in the subsequent section. Instead of using a diode rectifier to obtain the DC voltage to fed to the 3phase VSI, a DC voltage source is used. In order to produce the rated line voltage of $190 \mathrm{~V}$ (rms), which is equivalent to a phase voltage amplitude of $\frac{190}{\sqrt{3}} \sqrt{2}=155 \mathrm{~V}$, a DC voltage of $269 \mathrm{~V}$ at the input to the VSI is required (without over-modulation). This is because using SV-PWM, the maximum amplitude of the phase voltage that can be obtained without over-modulation is $\frac{V_{d c}}{\sqrt{3}}$. However, in the experiment, a DC voltage of $155 \mathrm{~V}$ is used (due to the available voltage source and safety reasons). Therefore, in the simulation, the same $\mathrm{DC}$ voltage of $155 \mathrm{~V}$ will be used. This means that the maximum frequency to maintain constant $\mathrm{V} / \mathrm{Hz}$ ratio will be less than the rated frequency of $50 \mathrm{~Hz}$. i.e. $f_{\max }=50 \frac{155}{269}=29 \mathrm{~Hz}$.

The motor is run based on the frequency profile $(\mathrm{Hz})$ (constructed using Signal builder block as shown in Figure 9(b)). In order to limit the slip to within small value, a rate limiter is inserted after the stator frequency reference. Without the rate limiter, a step-change in a frequency will result in a significant oscillation in the speed and torque before the steady-state speed and torque is reached. 
Table 1. Induction motor ratings and parameters

\begin{tabular}{cc}
\hline Parameters & rate \\
\hline Power, Voltage & $186 \mathrm{~W}, 190 \mathrm{~V}$ \\
Frequency, poles & $50 \mathrm{~Hz}, 4$ \\
$\mathrm{R}_{\mathrm{S}}$ & $10.35 \Omega$ \\
$\mathrm{R}_{\mathrm{r}}$ & $6.17 \Omega$ \\
$\mathrm{L}_{\mathrm{s}}$ & $0.2752 \mathrm{H}$ \\
$\mathrm{L}_{\mathrm{r}}$ & $0.2752 \mathrm{H}$ \\
$\mathrm{L}_{\mathrm{m}}$ & $0.2583 \mathrm{H}$ \\
$\mathrm{I}$ & $0.0014 \mathrm{~kg}-\mathrm{m}^{2}$ \\
$\mathrm{~B}$ & $0.002 \mathrm{Nm} / \mathrm{rad} / \mathrm{s}$ \\
\hline
\end{tabular}

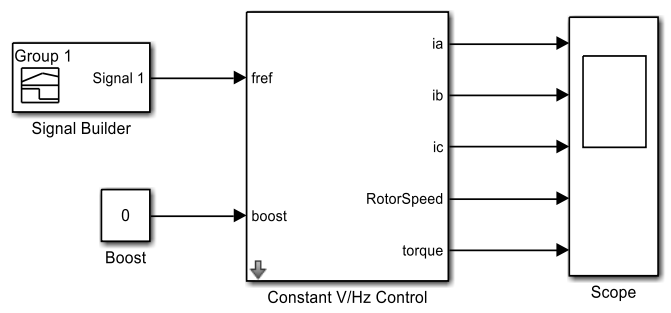

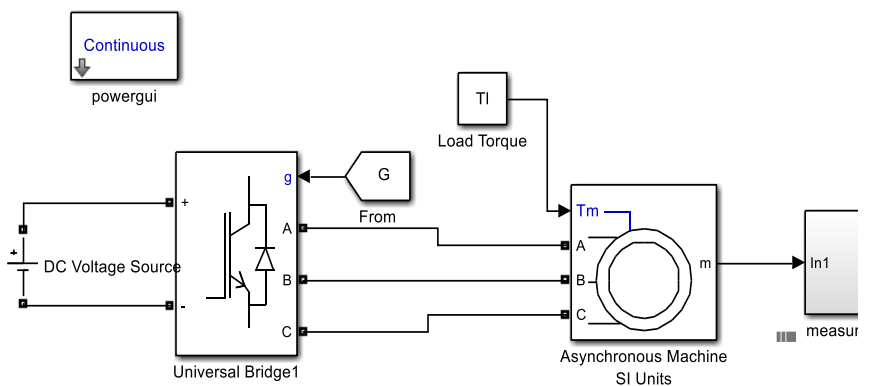

(a)

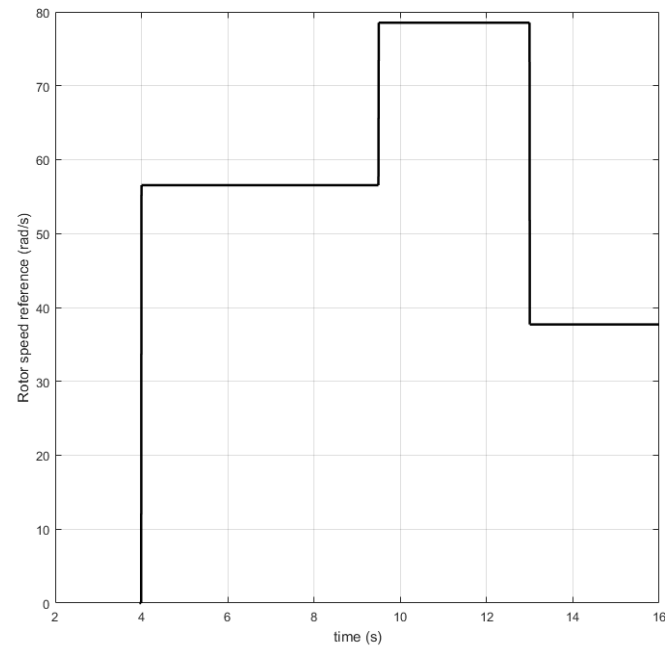

(b)

Figure 9. Simulation of constant V/Hz control of IM (a) Power system-simulink (b) Frequency reference profile

\subsection{Hardware implementation}

In order to evaluate the voltage and current of the IM driven by constant $\mathrm{V} / \mathrm{Hz}$, a real hardware experiment has been conducted. The block diagram of the experimental setup is shown in Figure 10 and the actual hardware setup is shown in Figure 11. The experiment utilized of a 3-phase VSI with gate drivers, a DC power supply, a $1 / 4 \mathrm{hp} \mathrm{3-phase} \mathrm{induction} \mathrm{motor} \mathrm{and} \mathrm{a} \mathrm{dSPACE} \mathrm{DS1104} \mathrm{controller} \mathrm{board.} \mathrm{The} \mathrm{constant}$ $\mathrm{V} / \mathrm{Hz}$ control is implemented using the DS1104 controller board with the C codes automatically generated from the Simulink model. The 3-phase VSI is constructed using three (3) units of 2-levels IGBTs with their dedicated freewheeling.

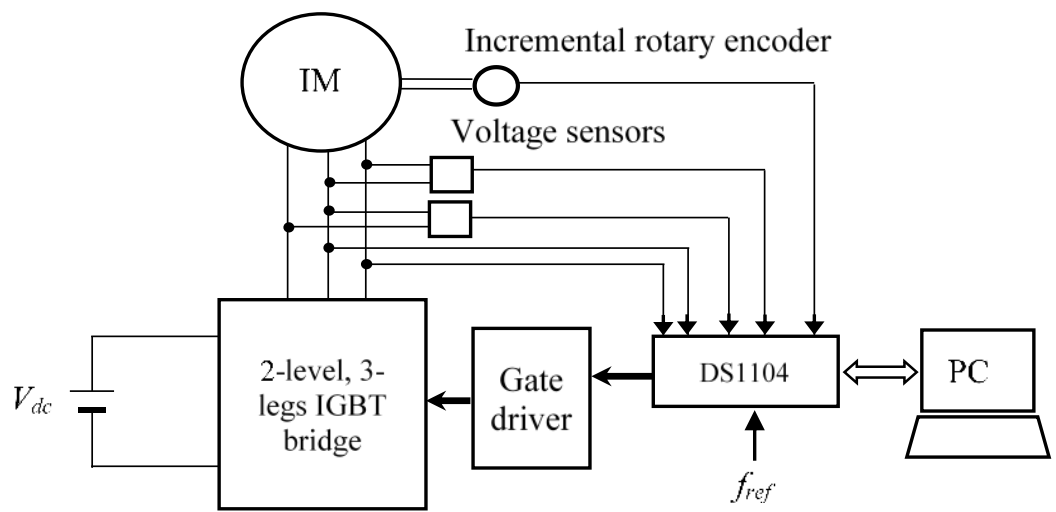

Figure 10. Experimental setup 
For monitoring purposes, two (2) current sensors are used to measure the phase currents. The ratings and parameters of the motor are similar to the one used in the simulation, which are as listed in Table 1. As mentioned earlier in the previous section, due to the limitation on the availability of the DC power supply and safety reasons, a DC voltage of up to only $155 \mathrm{~V}$ is used (which is similar to the simulation setting). Using SV-PWM, the maximum rms line-line voltage that can be achieved is

$$
V_{L-L, \max }=\frac{155}{\sqrt{3}} \frac{\sqrt{3}}{\sqrt{2}}=109.6 \mathrm{Vrms}
$$

For constant $\mathrm{V} / \mathrm{Hz}$ implementation, maximum frequency is therefore,

$$
f_{\max }=\frac{50}{190} 109.6 \approx 29 \mathrm{~Hz}
$$

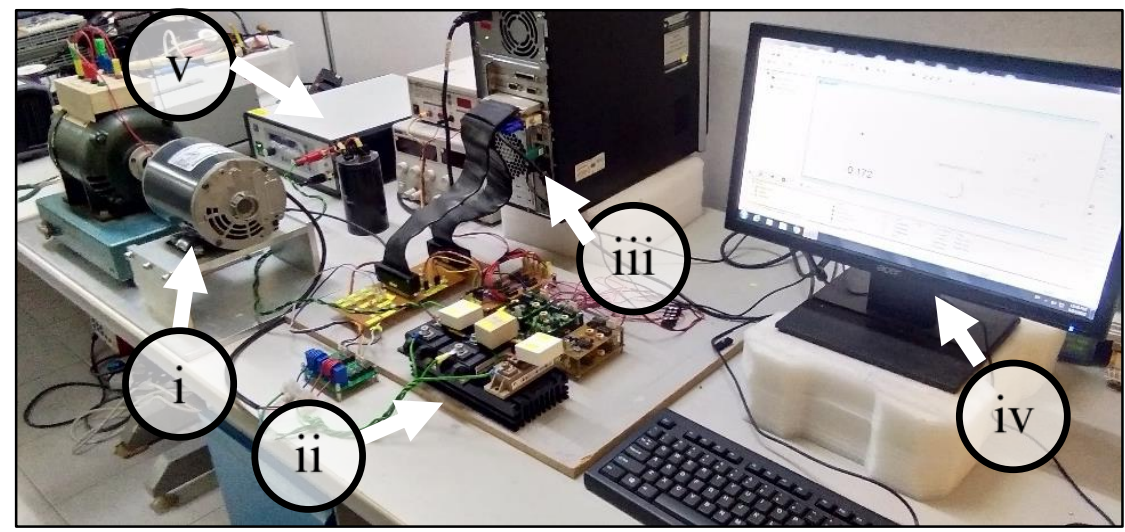

(i) IM under test (ii) IGBTs bridge (iii) DS1104 Controller (iv) User interface (v) DC power supply

Figure 11. Experimental setup

\section{RESULTS AND DISCUSSION}

\subsection{Simulation}

The simulation results of the stator line voltage, stator phase current, motor torque and rotor speed without and with a rate limiter are shown in Figure 12(a) and 12(b) respectively. In the simulation, the rate limiter is set to $100 \mathrm{~Hz} / \mathrm{s}$. A significant surge in the stator current (amplitude of beyond $2 \mathrm{~A}$ ), as well as a large oscillation in the torque response can be observed in the waveforms of Figure 12(a). Torque osccillation influence power efficiency and speed performance. In industrial application where tens to thousands horsepower IMs are utilized, this torque response can cause severe power disruption and damage to the drive system. With the limiter, frequency is gradually increased thus ensuring small slip operation. The amplitude of the current gradually increases and large oscillation in torque is removed.

In order to observe the transient-state behavior of the torque and speed when the frequency is increased from $0 \mathrm{~Hz}$ to $18 \mathrm{~Hz}$ and to $25 \mathrm{~Hz}$, and reduced to $12 \mathrm{~Hz}$, the torque-speed dynamic simulation results are superimposed onto the steady-state torque-speed characteristic of the motor at these three frequencies; these are shown in Figure 13(a) without the rate limiter, and Figure 13(b) with the rate limiter. As can be seen that with the insertion of the rate limiter, a significant reduction in the torque-speed oscillation is obtained.

Using MATLAB/Simulink it is also possible to perform FFT in order to view the frequency spectrum of the waveform and analyze the harmonics contents. Figure 13(a) and (b) shows the frequency spectrum of the line-line voltage and phase current of the IM, respectively, at the fundamental frequency of $25 \mathrm{~Hz}$. The figure clearly displays the harmonics contents of the waveforms at the multiples of the switching frequency, which is at $2000 \mathrm{~Hz}$. From the plot, the total harmonic distortions in Figure 14, the current and voltage homonic content obtained as $\mathrm{THD}_{\mathrm{I}}=5.39 \%$ and $\mathrm{THD}_{\mathrm{V}}=52.41 \%$ respectively. In comparison with the work presented in [13], with similar PWM technique (SVPWM) applied to 1hp IM (different motor parameters), the $\mathrm{THD}_{\mathrm{I}}=20.14 \%$ and $\mathrm{THD}_{\mathrm{V}}=64.78 \%$. Although both implemented similar modulation technique, both presented variation in power quality. Other than due to motor parameter variations, the 
results are also depending on the sampling time, waveform alighnment (SVPWM generation technique), type of switches and the inverter bridge topology, dc-link and others.
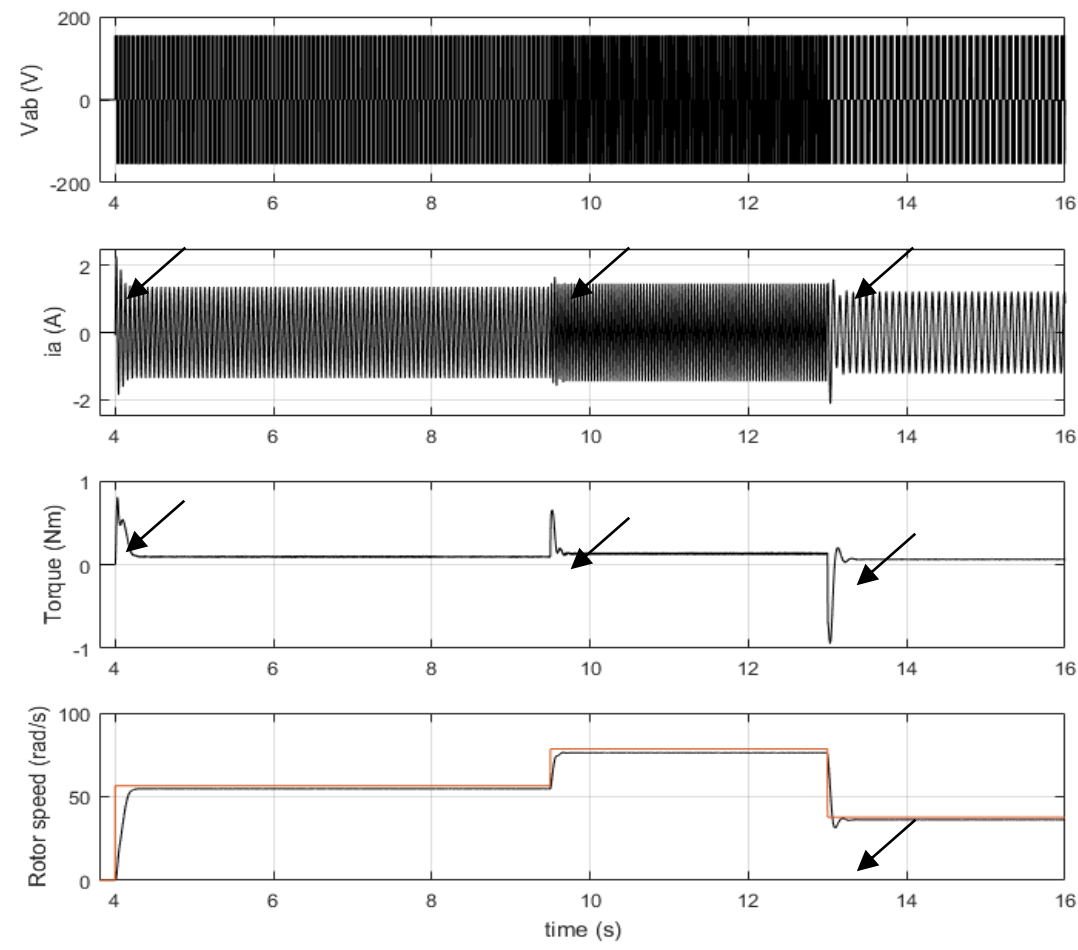

(a)
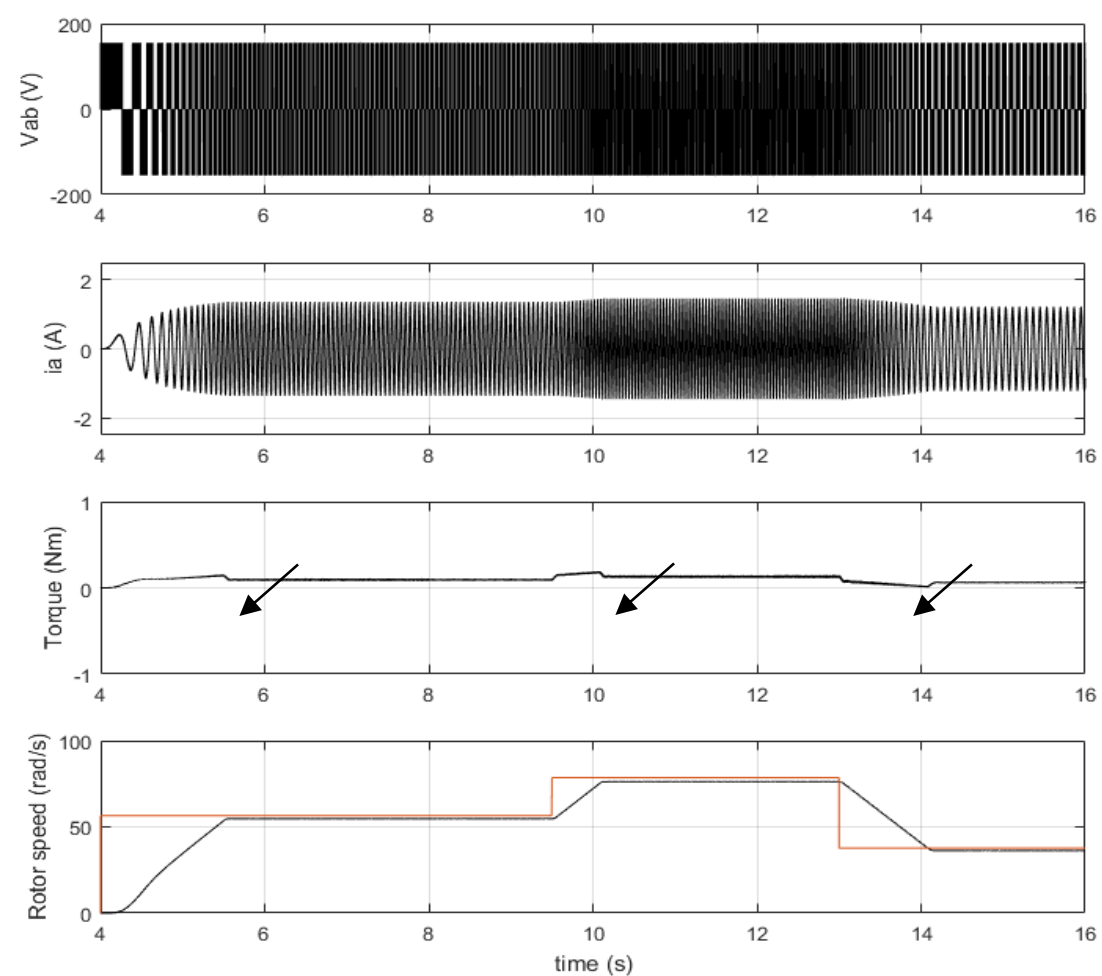

(b)

Figure 12. Simulation results of line voltage, phase current, torque, and rotor speed where the red line refers to reference speed (a) without rate limiter (b) with rate limiter 


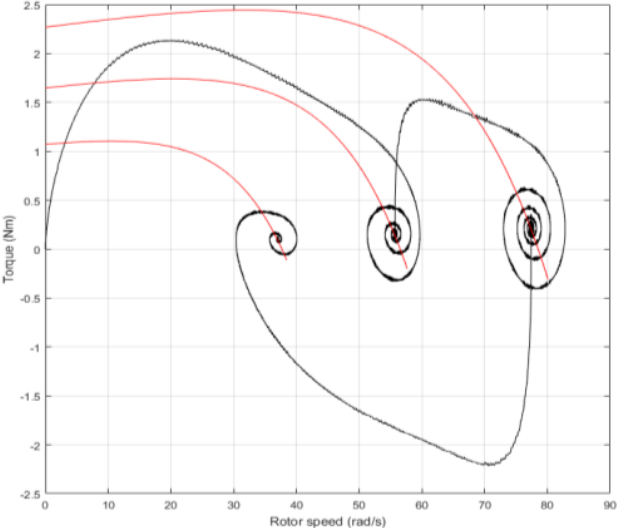

(a)

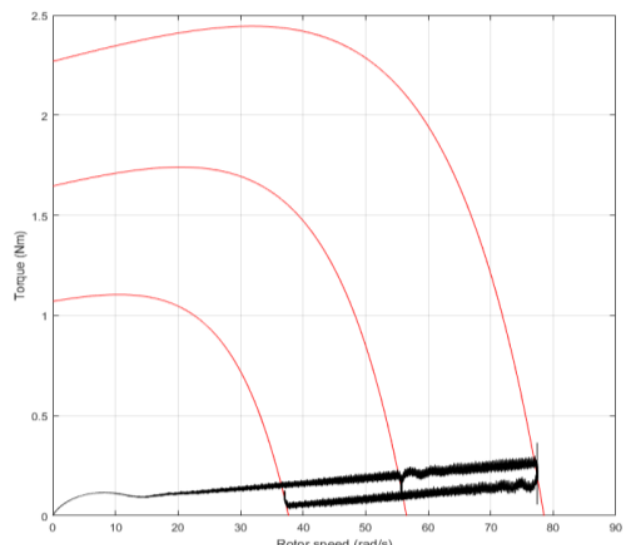

(b)

Figure 13. Transient $T-\omega$ behavior during the frequency variations: red line is the steady-state characteristic while the black line is the transient characteristics (a) without rate limiter (b) with rate limiter.
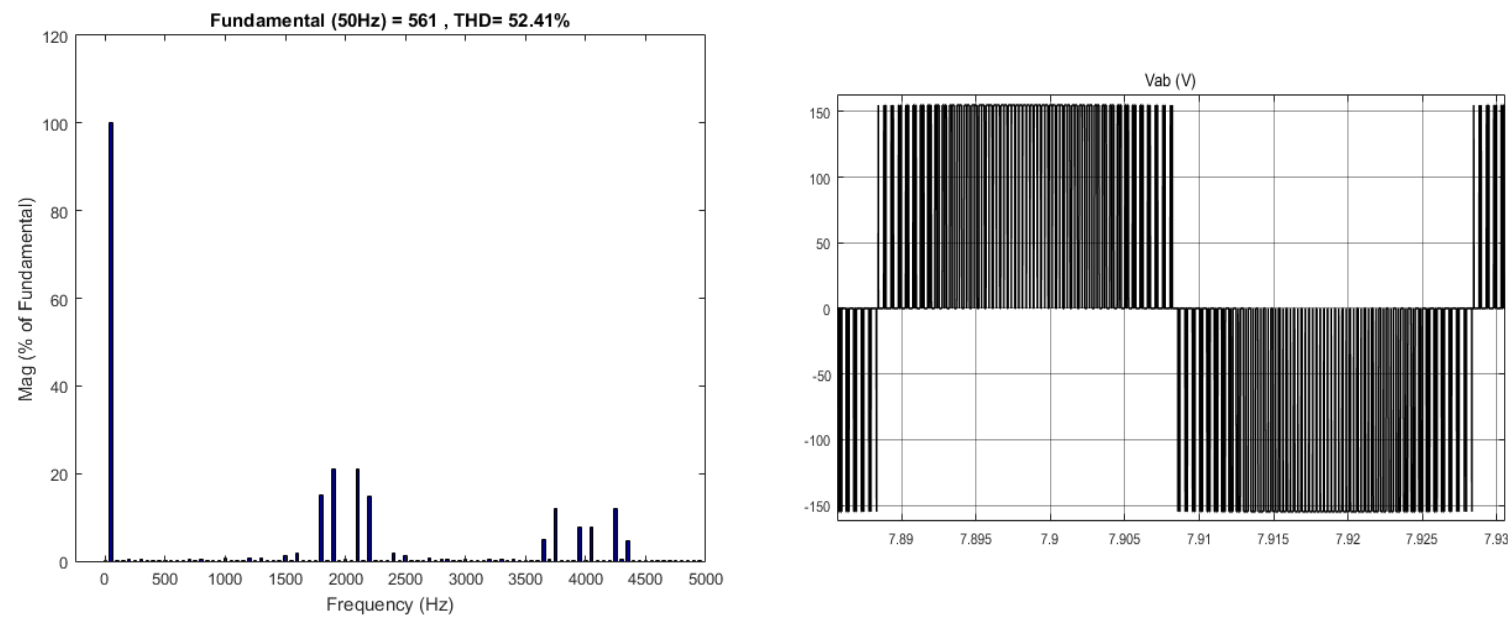

(a)
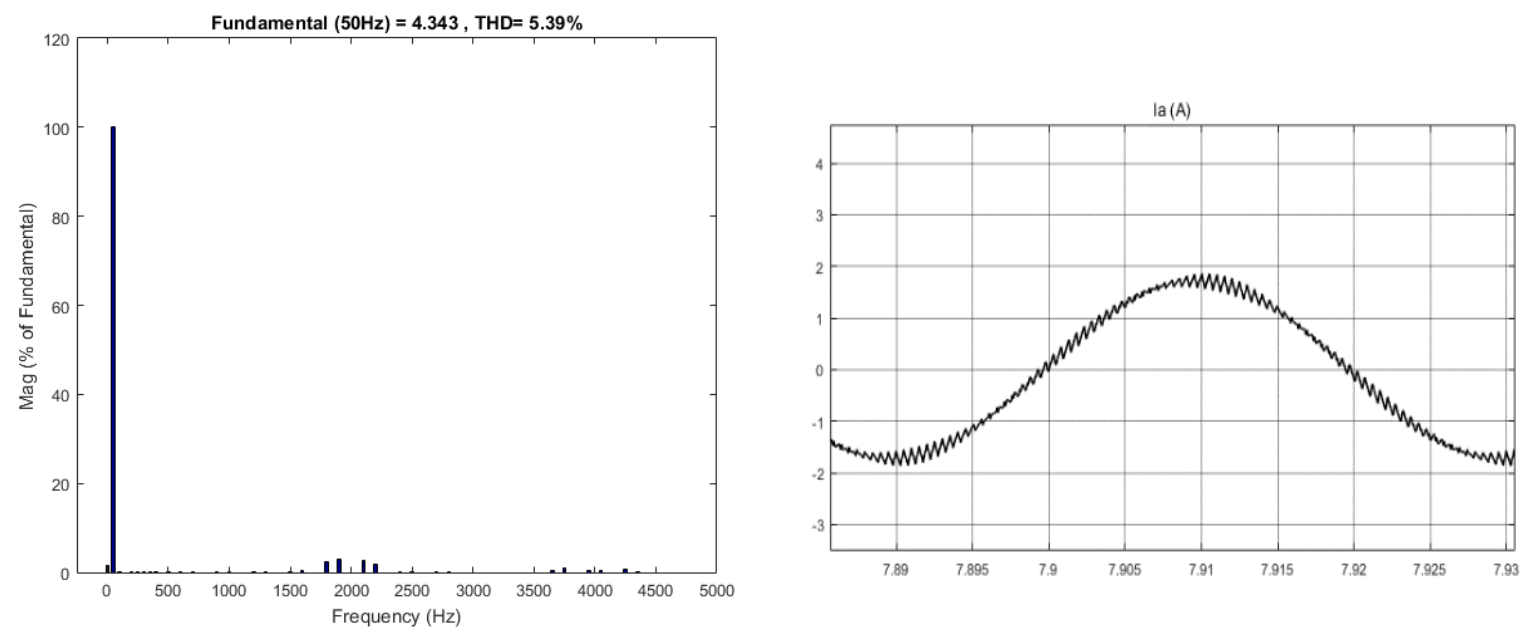

(b)

Figure 14. total harmonic distortions, (a) Line-line input voltage to the IM and Frequency spectrum obtained using FFT analysis tool in MATLAB at $25 \mathrm{~Hz}$; (b) Input phase current of the IM and frequency spectrum obtained using FFT analysis tool in MATLAB at $25 \mathrm{~Hz}$ 


\subsection{Real hardware implementation}

In the experiment, a frequency reference similar to the simulation is applied: step up from 0 to 18 $\mathrm{Hz}$, from $18 \mathrm{~Hz}$ to $25 \mathrm{~Hz}$ and finally it is step down to $12 \mathrm{~Hz}$. The waveforms for the phase current (phase A) and rotor speed without the rate limiter are shown in Figure 15 (a). Similar to the simulation results, without the rate limiter surges in the phase current can be observed for every step change in the frequency reference. On the other hand, the results with a rate limiter set to 12 is shown in Figure 15 (b). With the rate limiter, the frequency gradually increases (or decreases) thus avoiding large slip hence large surge in currents. A closer look at the phase currents during the step change in the frequency reference from 0 to $18 \mathrm{~Hz}$ is depicted in Figure 16(a) (without limiter) and Figure 16 (b) (with the limiter).
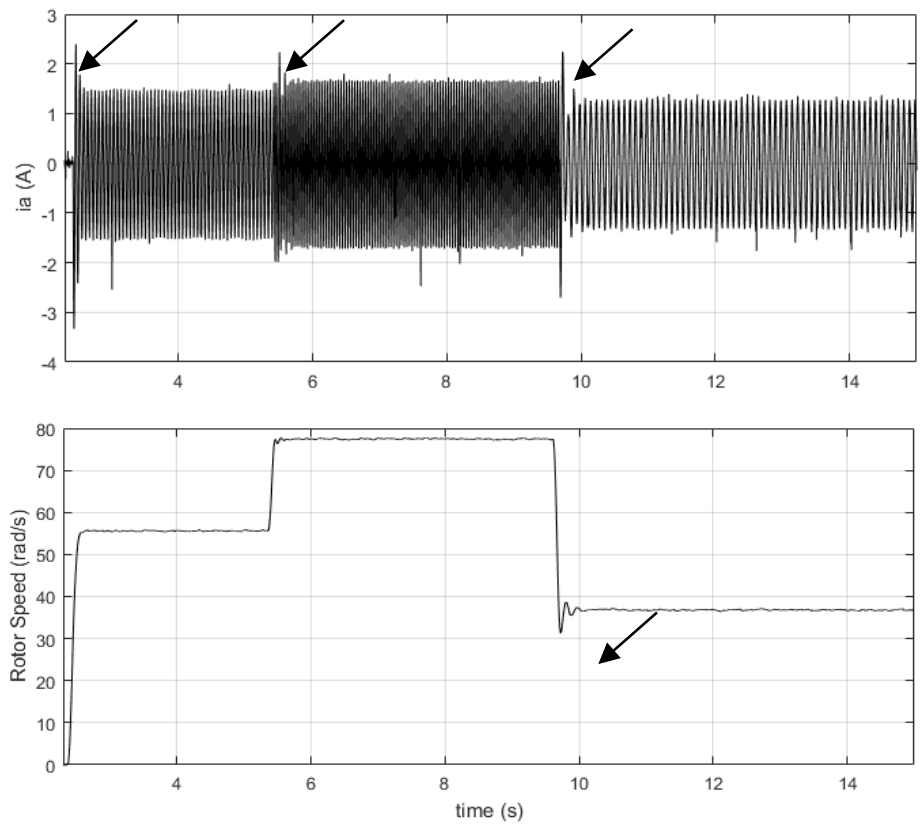

(a)
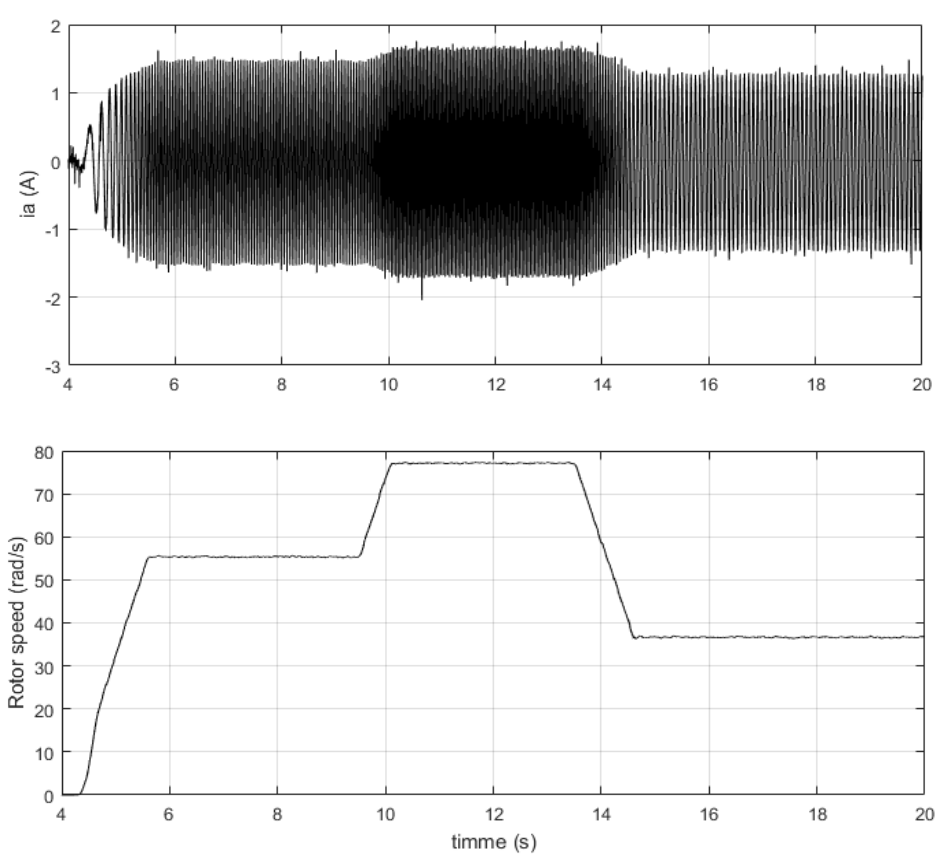

(b)

Figure 15. Stator phase current and rotor speed, (a) without rate limiter, (b) with rate limiter 

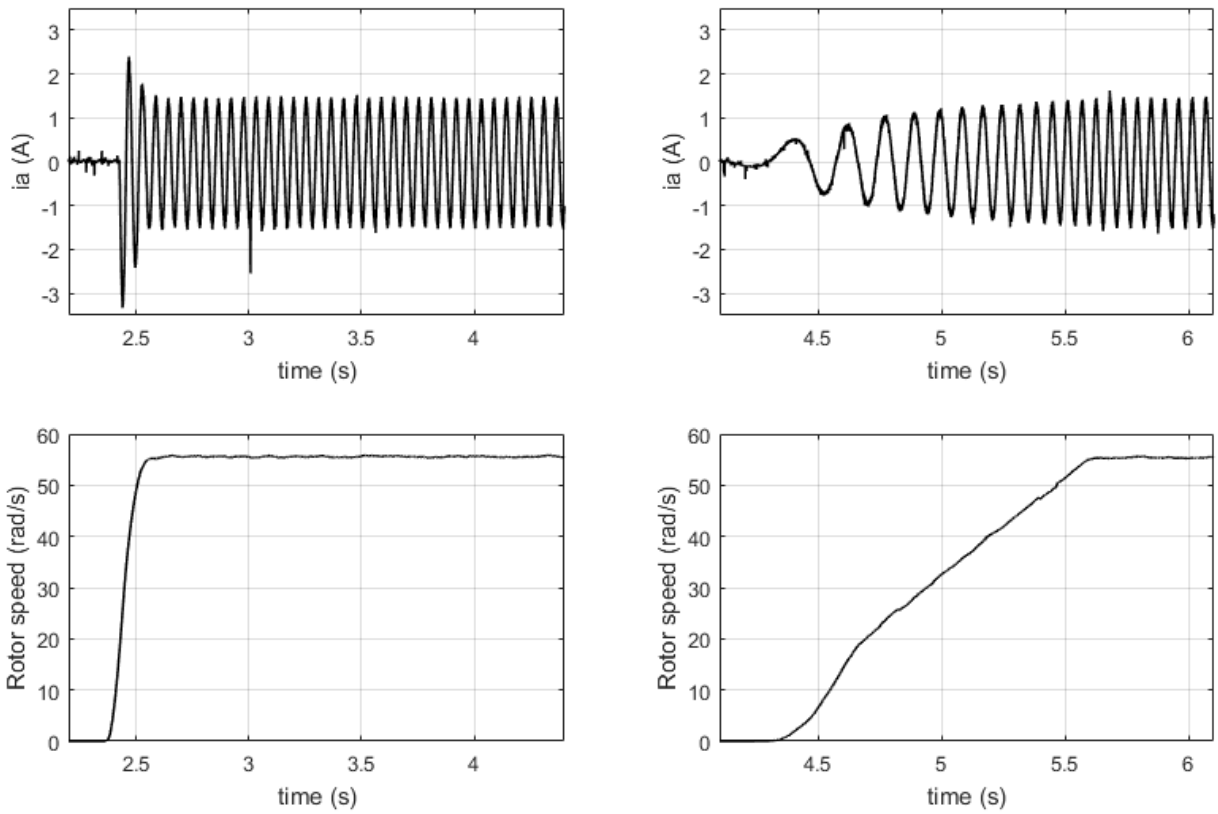

(a)

(b)

Figure 16. Closer look of the stator current and speed for a step frequency from $0 \mathrm{~Hz}$ to $18 \mathrm{~Hz}$, (a) without rate limiter, (b) with rate limiter
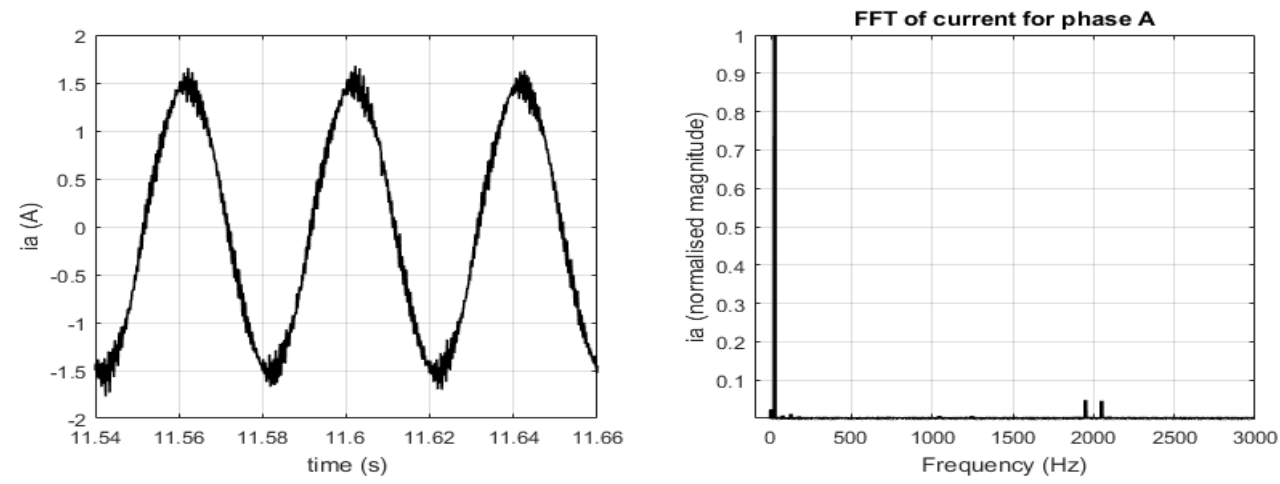

(a)
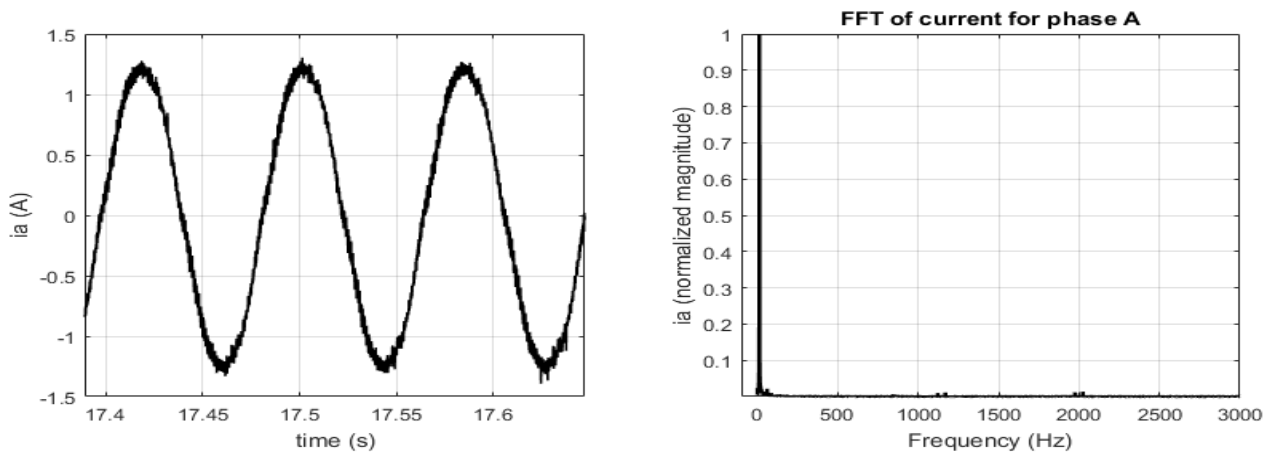

(b)

Figure 17. Closer look at the stator current and its frequency spectrum, (a) $25 \mathrm{~Hz}$; (b) $12 \mathrm{~Hz}$ 
A closer look at the current waveform when $f_{\text {ref }}=25 \mathrm{~Hz}$ and $12 \mathrm{~Hz}$ and its respective Fourier analysis are shown in Figure 16 (a) and (b) respectively. The high-frequency harmonic contents around the switching frequency of $2000 \mathrm{~Hz}$ can be observed for both cases. The voltage waveform presents more spike noises in constrast to current waveform, this is due to the natural characteristic of IM (RL load) that tend to filter high frequency noices of current. In comparison with the experimental work in [13], an analog S-PWM inverter is used to drive other IM with similar hp $(1 / 4 \mathrm{hp})$. The author claimed that the IM run at rated speed. However, the stator voltage and current waveforms are not presented in report due to the limitation of measurement instrument. It is imported to know that the integrity of waveforms is highly depend to the type and quality of measurement instruments. Since, both VSI and IM are conducting EMI, it is important to intergrate proper EMI management method to the measurement instrument. The easiest way to capture the realtime voltage and current waveform is by using a high-speed oscilloscope with their dedicated differential probe for voltage and current probe those tools that specifically designed with EMI filtering and management.

\section{CONCLUSION}

An open-loop constant $\mathrm{V} / \mathrm{Hz}$ IM drive is one of the most popular drives for industrial applications. The main component in this system is the inverter unit. Apart from other modulation techniques, SV-PWM is the most commonly applied for VSI. Constant V/Hz allows speed and torque regulation of the IM, therefore, besides improving power efficiency, the dependency towards mechanical gear can also be reduced or eliminated. With proper electrical sensors installation and EMI management, feedback control can be adopted. Opening ways for dynamic adaptation and automation. However, there are several issues that arise related to its robustness when operating in extreme environments that need to be addressed before replacing the mechanical control mechanism. The fundamental concepts, main control elements, and commonly known problems of a constant V/Hz IM drive has been discussed. MATLAB/Simulink simulation and DS1104 controller board based-laboratory-scale implementation results and discussion has been presented. It is expected that through this, interested practicing engineers could attain a sufficient understanding to assist decision-making and develop confidence to communicate ideas in this topic.

\section{REFERENCES}

[1] Aswin uvaraj Ganesan and L. N. Chokkalingam, "Single phase direct on line synchronous motor for a specific application in comparison with an induction motor," Int. Trans. Electr. energy Syst., vol. 29, no. 4, 2019.

[2] K. Pillay, M. Nour, K. H. Yang, D. N. D. Harun, and L. K. Haw, "Assessment and Comparison of Conventional Motor Starters and Modern Power Electronic Drives for Induction Motor Starting Characteristics," in IEEE Symposium on Industrial Electronics and Applications, 2009, pp. 584-589.

[3] J. Larabee, M. Ieee, B. Pellegrino, and B. Flick, "Induction motor starting methods and issues," in Record of Conference Papers Industry Applications Society 52nd Annual Petroleum and Chemical Industry Conference, 2005, pp. 217-222.

[4] M. Habyarimana and D. G. Dorrell, "Methods to Reduce the Starting Current of an Induction Motor," in IEEE International Conference on Power, Control, Signals and Instrumentation Engineering (ICPCSI), 2017, pp. 34-38.

[5] M. Frini, A. Soualhi, and M. El Badaoui, "Gear faults diagnosis based on the geometric indicators of electrical signals in three-phase induction motors," Mech. Mach. Theory, vol. 138, pp. 1-15, 2019.

[6] C. P. Mehdi Mehrgou, Inigo Garcia de Madinabeitia, Bernhard Graf, Franz Zieher, "NVH Aspects of Electric Drives-Integration of Electric Machine, Gearbox and Inverter," in SAE Technical Paper 2018-01-1556, 2018, p. 6.

[7] S. Vallachira, M. Orkisz, M. Norrlof, and S. Butail, "Data-Driven Gearbox Failure Detection in Industrial Robots," IEEE Trans. Ind. Informatics, vol. 16, no. 1, pp. 193-201, 2020.

[8] Y. Seki, "Present Status and Trends of Power Semiconductor Devices," Power, vol. 47, no. 2, pp. 34-36, 2000.

[9] T. G. Wilson, "The evolution of power electronics," IEEE Trans. Power Electron., vol. 15, no. 3, pp. 439-446, 2000.

[10] IEA, “2018 Energy Efficiency Indicators Highlights,” Int. Energy Agency, p. 191, 2018.

[11] U. Choi, "Separation of Wear-Out Failure Modes of IGBT Modules in Grid-Connected Inverter Systems," IEEE Trans. Power Electron., vol. 33, no. 7, pp. 6217-6223, 2018.

[12] Z. Raud and V. Vodovozov, "Remote Training with Self-Assessment in Electrical Engineering," Int. J. Educ. Pedagog. Sci., vol. 10, no. 1, pp. 46-51, 2016.

[13] S. N. Mahsahirun, "Development of S-PWM voltage source inverter for induction motor drives," Universiti Malaysia Pahang, 2017.

[14] K. S. Lee, S. H. Lee, J. H. Park, J. M. Kim, and J. Y. Choi, "Experimental and Analytical Study of Single-Phase Squirrel-Cage Induction Motor Considering End-Ring Porosity Rate," IEEE Trans. Magn., vol. 53, no. 11, 2017.

[15] N. Tesla, "A new system of alternate current motors and transformers," Proceedings of the IEEE, vol. 72, no. 2, pp. $165-173$, Feb-1984.

[16] W. Leonhard, "Field orientation for controlling AC machines - Principle and application," in Third International Conference on Power Electronics and Variable-Speed Drives, 1988.

[17] I. Takahashi and Y. Ohmori, "High-performance direct torque control of an induction motor," IEEE Trans. Ind. 
Appl., vol. 25, no. 2, pp. 257-264, 1989.

[18] G. Sieklucki, "An Investigation into the Induction Motor of Tesla Model S Vehicle," in 2018 International Symposium on Electrical Machines (SME), 2018, pp. 1-6.

[19] T. Alban and A. Billaud, "Selection and Tests Of Innovative Variable Speed Motor-Compressor Solutions For A 55mw Full Electric Offshore Platform Maximizing Availability And Efficiency," IEEE Trans. Ind. Appl., vol. PP, no. c, p. 1, 2019.

[20] O. Tikhonova, I. Malygin, and A. Plastun, "Electromagnetic calculation for induction motors of various designs by "ANSYS Maxwell," in 2017 International Conference on Industrial Engineering, Applications and Manufacturing, 2017.

[21] A. V Radun, "Development of Dynamic Magnetic Circuit Models Including Iron Saturation and Losses," IEEE Trans. Magn., vol. 50, no. 5, pp. 1-10, 2014.

[22] G. R. Slemon, "Modelling of induction machines for electric drives," IEEE Trans. Ind. Appl., vol. 25, no. 6, pp. 1126-1131, 1989.

[23] K. Sheng, B. W. Williams, X. He, Z. Qian, and S. J. Finney, "Measurement of IGBT switching frequency limits," in 30th Annual IEEE Power Electronics Specialists Conference, 1999, vol. 1, pp. 376-380.

[24] Z. J. Shen and I. Omura, "Power semiconductor devices for hybrid, electric, and fuel cell vehicles," in Proceedings of the IEEE, 2007, vol. 95, no. 4, pp. 778-789.

[25] M. Weinmann, S. Zeh, and N.-V. Olarescu, "EP2536019A1: Method for controlling an inverter," 2012.

[26] A. B. David, T. A. Nergaard, and H. Hofmann, "US7821224: Voltage estimation feedback of overmodulated signal for an electrical vehicle," 2008.

[27] H. W. Van Der Broeck, H.-C. Skudelny, and G. V. Stanke, "Analysis and Realization of a Pulsewidth Modulator Based on Voltage Space Vectors," IEEE Trans. Ind. Appl., vol. 24, no. 1, pp. 142-150, 1988.

[28] S. R. Bowes, "New sinusoidal pulsewidth-modulated invertor," Proc. Inst. Electr. Eng., vol. 122, no. 11, p. 1279, 1975.

[29] H. W. Van Der Broeck, H.-C. Skudelny, and G. V. Stanke, "Analysis and Realization of a Pulsewidth Modulator Based on Voltage Space Vectors," IEEE Trans. Ind. Appl., vol. 24, no. 8716204, pp. 142-150, 1988.

[30] S. Ogasawara, H. Akagi, and A. Nabae, "A novel PWM scheme of voltage source inverters based on space vector theory," Arch. für Elektrotechnik, vol. 74, no. 1, pp. 33-41, 1990.

[31] E. Clarke, Circuit Analysis of A-C Power Systems; Symmetrical and Related Components Volume 1. New York: John Wiley \& Sons Inc., 1943.

[32] R. H. Park, "Two-Reaction Theory of Synchronous Machines: Generalized Method of Analysis-Part I," Trans. Am. Inst. Electr. Eng., vol. 48, no. 3, pp. 716-727, 1929.

[33] A. Tripathi and G. Narayanan, "Influence of three-phase symmetry on pulsating torque in induction motor drives," in 2016 7th India International Conference on Power Electronics (IICPE), 2016, pp. 1-6.

\section{BIOGRAPHIES OF AUTHORS}

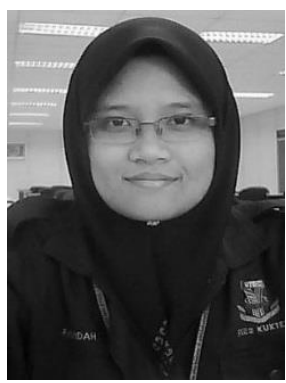

Siti Nursyuhada Mahsahirun received the B.Eng. degree in electrical engineering in 2010 and M.Eng. degree in mechatronics engineering in 2017 from Universiti Malaysia Pahang (UMP), Malaysia. She is now enrolled a Ph.D. degree in mechatronics engineering under Faculty of Manufacturing and Mechatronics Engineering Technology, UMP and UTM-Proton Future Drives Laboratory, Johor, Malaysia. Her main research interests are induction motor drive systems, artificial neural network and FPGA.

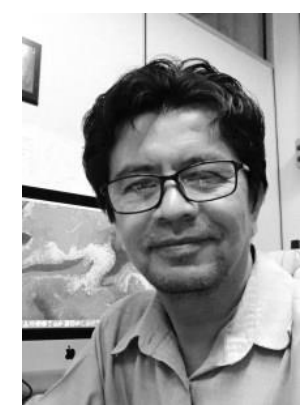

Nik Rumzi Nik Idris received the B.Eng. degree in electrical engineering from the University of Wollongong, N.S.W., Australia, in 1989, the M.Sc. degree in power electronics from Bradford University, West Yorkshire, U.K., in 1993, and the Ph.D. degree from Universiti Teknologi Malaysia (UTM), Johor Bahru, Malaysia, in 2000. He is currently an associate professor at the UTM, the Head of the Power Electronics and Drives Research Group, and Head of UTM-Proton Future Drive Laboratory. His current research interests include control of ac drive systems and DSP applications in power electronic systems. Dr. Idris is also the Past Chair of the IEEE Power Electronics Society, Malaysia Chapter, and is also a senior member of the IEEE. 


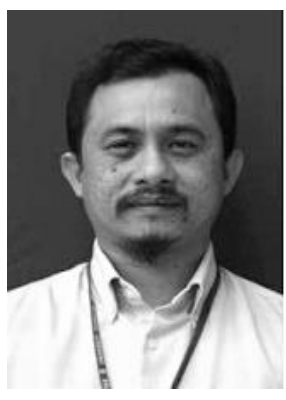

Zulkifli Md Yusof received the B.Eng electrical engineering from University of Arizona in 1989 where he exposed to microelectronics field and involve in the university's Network Transmission Line Software Development. He obtained his M.Sc. in electrical engineering from Washington State University (WSU), U.S.A. focusing in semiconductor device modeling and transport characteristic of wide bandgap material. He is currently a Senior Lecturer of the Faculty of Manufacturing and Mechatronics Engineering Technology at Universiti Malaysia Pahang (UMP), Malaysia. His current research expertise is in microelectronis and computer enginering field, VLSI routing, compressed memory architecture and algorithms optimization. He was an engineer in Hitachi Semiconductor in Penang before appointed as asistant lecturer in UTM, Kuala Lumpur in 1989 and later a senior lecturer at the Department of Microelectronics and Computer Engineering, Faculty of Electrical Engineering, Universiti Teknologi Malaysia (UTM), Johor Bahru, Malaysia. He is the former Head of Mechatronics Programme in the Faculty Manufacturing Engineering, UMP.

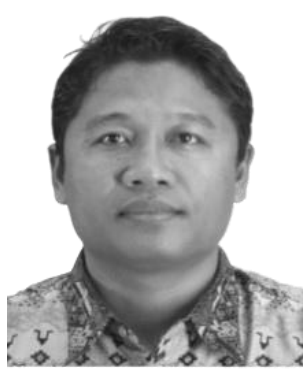

Tole Sutikno is a Lecturer in Electrical Engineering Department at the Universitad Ahmad Dahlan (UAD), Yogyakarta, Indonesia. He received his B.Eng., M.Eng. and Ph.D. degree in Electrical Engineering from Universitas Diponegoro (Semarang, Indonesia), Universitas Gadjah Mada (Yogyakarta, Indonesia) and Universiti Teknologi Malaysia (Johor, Malaysia), in 1999, 2004 and 2016, respectively. He has been an Associate Professor in UAD, Yogyakarta, Indonesia since 2008. He is currently an Editor-in-Chief of the TELKOMNIKA, Director of LPPI UAD, and the Head of the Embedded Systems and Power Electronics Research Group. His research interests include the field of digital design, industrial electronics, industrial informatics, power electronics, motor drives, industrial applications, FPGA applications, artificial intelligence, intelligent control, embedded system and digital library. 